\title{
Shifting Spatial Patterns Of A Monocentric Metropolitan Area: The Evolution Of An Employment Cluster In The Buffalo-Niagara Falls, New York Metropolitan Statistical Area (MSA): 1990-2000
}

Craig D. Rogers, (E-mail: rogersc@canisius.edu), Canisius College

\begin{abstract}
These findings are contrary to the established economic and geography literature that strongly suggests employment suburbanization has and will continue to create employment centers beyond the central city in metropolitan areas.
\end{abstract}

\section{INTRODUCTION}

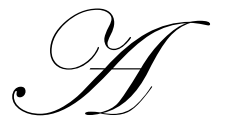

$s$ is true of many former industrial metropolitan regions, the Buffalo-Niagara Falls, New York metropolitan economy has trailed that of other major metropolitan areas in New York State, as well as nationally. The region's loss of population and employment has been well documented. Indeed, Buffalo-Niagara Falls' employment and population patterns reveal a metropolitan economic structure that is quite contrary to the well accepted premise of a polycentric model of metropolitan economic development.

Since the 1970s, the premise of polycentric based economic activity in metropolitan areas has dominated metropolitan structure and economic development literature. Undoubtedly this is true for most metropolitan areas in the United States. However, there exist several metropolitan areas whose spatial distribution of economic activity yield not multiple centers of economic activity, but rather elongated versions of a monocentric model of metropolitan economic activity. The Buffalo-Niagara Falls metropolitan statistical area (MSA) is a modern version of a monocentric MSA. Intra-metropolitan employment shifts in monocentric metropolitan areas experiencing net population and employment loss have received relatively little empirical investigation.

The spatial changes in the composition and structure of employment centers are important considerations that are manifested in metropolitan governance public policy issues. Specifically, the intra-metropolitan shifts in employment directly impact regional planning and transportation issues, such as urban sprawl and regional governance. In addition, changes in the location of employment centers and population underscore the shifting pattern of political power between central cities and their outlying inner-ring, outer-ring and ex-urban suburban areas.

This paper is divided into four sections: (section 1.1), a brief overview of the major changes in the composition and structure of the employment and population in the Buffalo metropolitan statistical area; (section 1.2), the methodology used to define and categorized employment centers; (section 1.3), data results; and (section 1.4), the conclusion. 


\section{CHANGES IN POPULATION, EMPLOYMENT, AND ECONOMIC SECTORS: 1990-2000}

The Buffalo metropolitan statistical area has undergone significant industrial restructuring since its heyday as an automotive industrial supplier, flour milling and industrial chemical processor center. The shift in employment and population has permanently altered the structure and governance of the metropolitan area. Since the mid 1970s, the balance of economic and political power has shifted from the central cities of the Buffalo metropolitan area to its suburbs. Buffalo's metropolitan economy has suffered multiple blows, among them a thirty year decline in population and economic activity and the change in distribution of employment and population within the metropolitan area.

The population and employment suburbanization that began in the late 1960s has continued unabated, as illustrated in Charts 1 and 2. This migration has been uneven in terms of suburban location. The pattern of suburbanization has generally followed national patterns, demonstrated by the fact that inner-ring suburbs were the initial destination for many central city families. Later, the outer-ring and exurban areas experienced relatively explosive population growth as household incomes increased and employment opportunities became more widely available.

Buffalo-Niagara Falls metropolitan area population decreased by $1.61 \%$ during the 1990 s as the average U.S. metropolitan population grew by $13.9 \%$. The population loss in the Buffalo metropolitan area was spatially uneven. Central cities lost population as suburbia gained residents. Since the 1970s, the metropolitan population has shifted from the central cities, and today, more than $64 \%$ of the metropolitan area's population resides in its suburbs.

Population decline in Buffalo's metropolitan central cities ${ }^{1}$ accounted for the entire population loss in the metropolitan area. While suburban population in the area grew by more than $6 \%$, it was not able to offset a net decline of more than $13 \%$ in central city population during the 1990s. The continuation of population suburbanization underscores the shifting location of firms and employment ${ }^{2}$.

Shifting employment in the metropolitan area has been significant and mirrors the 1990's population suburbanization. Unlike other major metropolitan areas, the Buffalo metropolitan area did not participate in the U.S. economic expansion of the 1990s. While U.S. metropolitan employment grew by $11 \%$ during the 1990s, Buffalo metropolitan area employment decreased by $1.04 \%$ during the same time period. Buffalo's metropolitan employment change has been spatially uneven.

Buffalo-Niagara's suburban areas enjoyed increased employment across the three economic sectors as the metropolitan area's central cities experienced net employment losses. The distribution of employment by economic sectors remained unchanged during the 1990s, as illustrated in Chart 3. The stability in the distribution of employment by economic sectors masks the intra-metropolitan spatial changes by economic sectors ${ }^{3}$.

Suburban employment expansion was led by the public sector and the non-profit private sectors. Suburban employment grew by more than three percent $(3.12 \%)$ at the same time that the area's central cities experienced employment losses, exceeding eleven percent $(11.01 \%)$. There was great variance in the employment changes by economic sectors. Suburban public sector and non-profit private sector employment grew faster than suburban private sector employment. The opposite held true for central city employment in these three sectors. Each experienced a loss in employment in the central cities of the Buffalo metropolitan area.

\footnotetext{
${ }^{1}$ The Buffalo-Niagara Falls, New York metropolitan statistical area consists of two counties: (1) Erie and (2) Niagara Falls and six central cities: (1) Buffalo; (2) Niagara Falls; (3) Lackawanna; (4) Tonawanda; (5) Lockport; and (6) North Tonawanda

${ }^{2}$ One major limitation of using Census data is the inability to disaggregate full-time and part-time employment. Throughout this paper, employment refers to full-time and part-time employment of individuals 16 years and over as defined by the Census.

${ }^{3}$ The focus of this paper is on paid-employment and thus self-employment and unpaid family workers were excluded from the analysis.
} 
As with the rest of the nation, the Buffalo metropolitan economy is dominated by the private sector, which accounts for more than seventy-two percent (72\%) of total employment in the area. Within the private sector, the non-profit sector accounts for approximately ten percent of all of the region's jobs.

Chart 4 illustrates the increased concentration of employment in the suburbs. With more than two-thirds of the area's employment based there, suburban employment has expanded as central city employment has decreased. Employment losses were uneven across the major industrial categories.

The Buffalo-Niagara Falls metropolitan economic business landscape is dominated by small privately owned firms. The region is home to very few regional headquarters of multinational corporations. Of special concern is the fact that the change in the private sector employment was largely due to the expansion of small private sector firms located predominately in suburbia versus the traditional business centers of the central business district of Buffalo, NY.

The spatial change in the location of employment has been fueled by the expansion of small private sectors firms in the metropolitan area. White, Binkley and Osterman (1993) examine employment growth in the suburbs as fueled by the expansion of new small private sector firm growth. Their research concluded that these firms did not relocate from the central cities of the metropolitan area; rather they are new firm births. The expansion of employment and population to the suburbs of this metropolitan area suggests that over time those metropolitan economies will evolve from a monocentric economic center to a polycentric model of metropolitan economic activity. The next section details the methodology used to construct and identify employment centers in the Buffalo metropolitan area.

\section{EMPLOYMENT CENTERS METHODOLOGY}

Unlike other studies that examined the clustering of employment in metropolitan areas, this paper incorporates two comparative methods to assist in assessing the number of employment centers in the Buffalo metropolitan area. The traditional methodology in previous studies used a minimum traffic analysis zones (TAZs) employment density threshold to identify individual TAZs, and then combine adjacent TAZs meeting the minimum employment density level into a group of TAZs whose collective TAZ employment exceeded a minimum employment level. This paper adopts this TAZ employment density methodology and also uses spatial autocorrelation tools to identify employment centers in the metropolitan area. The spatial autocorrelation tools used here are embedded in a geographical information systems statistical program. ${ }^{4}$

As noted by Forstall and Greene (1997), previous studies have developed various definitions and methodological techniques to measure the spatial concentration of employment within a metropolitan area. Debate exists in the literature on the construction of employment centers, focusing on such points as which is the appropriate spatial unit to use and on the multiple definitions of an employment center (see Erickson, (1986), McDonald and Prather (1994), and McMillen (2003)). Studies that have researched the employment centers of metropolitan areas have utilized a variety of spatial measurement units from TAZs (Giuliano and Small, (1991), Bogart and Ferry, (1999)), census tracts (Forstall and Greene, 1997) and, lastly, zip codes. Each spatial measurement unit has its advantages and disadvantages. ${ }^{5}$ In keeping with the methodology used by Giuliano and Small (1991) and Forstall and Greene (1997), this paper utilizes TAZs as the spatial unit of measurement.

The second problem area is the multiple labels assigned to the definition of a concentration of employment. There are several definitions labels that are currently used by researchers who are investigating essentially the same phenomena of the changing spatial distribution of employment beyond central city boundaries. Labels such as: edge city employment, minicity, suburban center, and suburban nucleation are just a few that have been used. Each label

\footnotetext{
${ }^{4} \mathrm{GeoDa}$ is the geographical information systems statistical software program used in this paper. This program is available at no cost at the following website: https://www.geoda.uiuc.edu/

${ }^{5}$ See Forstall and Greene (1997) for a summary of the advantages and disadvantages of each spatial measurement unit.
} 
referencing the spatial distribution of employment has spawned its own unique methodology of measuring employment concentration.

Fortunately, one characteristic is shared by the major methodological methods: the construction of a density measure (i.e. employment per square mile) as noted by McMillen and McDonald (1990), Giuliano and Small (1991), and Anderson and Bogart (2001). This paper follows the general methodology developed by Giuliano and Small in their 1991 study of employment centers in the sprawling Los Angeles metropolitan statistical area (MSA).

As defined by McMillen and McDonald (1990), Giuliano and Small (1991), and Anderson and Bogart (2001), employment centers are areas of high density and employment levels. Using the employment center methodology developed by McMillen and McDonald (1990), we defined these centers as clusters of traffic analysis zones (TAZs) that meet three criteria: (1) individual TAZs have a minimum employment level of 10,000 employees per square mile; (2) the employment of the clustered TAZs are equal to or exceed 10,000 employees; and (3) the TAZs are physically adjacent to each other.

Based on the methodology noted above and using Census of Transportation Planning Package (CTPP) data, 26 TAZs met the minimum employment density threshold in 1990 and 23 TAZs in 2000. The techniques described above are quite sensitive to the minimum TAZ employment density threshold used. In response to this issue, I also utilize spatial autocorrelation as the spatial statistical technique to identify employment centers in the metropolitan area. The results are strikingly similar, whether using the TAZ employment density method or spatial autocorrelation and are discussed in the next section.

\section{TAZ EMPLOYMENT DENSITY AND SPATIAL AUTOCORRELATION EMPLOYMENT CENTER ANALYSIS: 1990-2000}

Analysis of the TAZ employment density and spatial autocorrelation data highlights three interesting and surprising revelations. First, there exists only one significant employment center in the Buffalo-Niagara Falls metropolitan statistical area. This elongated employment center is concentrated in Buffalo city, not in the suburban area of the metropolitan area. Finally, there has been relatively little change in the physical location of the employment center during the 1990s.

The most surprising finding, using either the TAZ employment cluster method or spatial autocorrelation, is that there exists only one elongated employment center in the Buffalo-Niagara Falls metropolitan statistical area. This center consisted of 20 individual TAZs in 2000, a decrease of only 1 TAZ from 1990 using the TAZ employment density ${ }^{6}$. There is only a one TAZ difference between the TAZs identified by this method and those identified using spatial autocorrelation. This employment center represented approximately 11 percent of the total Buffalo metropolitan employment in 2000. The industrial characteristic of the employment center did not changed during the 1990s.

Although the employment center represents a relatively small percentage of overall metropolitan employment, it does represent much larger percentages of key industrial sectors. Chart 5 highlights the relative concentration of the employment center employment across the major industrial sectors. The employment center represents a relative concentration of producer services industries and the location of a majority of the public administration employment.

The minor TAZ change in the employment center represents an intra-central city change, not an intrametropolitan change. Map 1 shows that the employment center is spatially located within the city of Buffalo. These two findings are consistent using the TAZ employment clustering technique or using spatial autocorrelation. Map 2 is a LISA cluster map that highlights the spatial autocorrelation of the 2000 TAZ employment density. ${ }^{7}$

\footnotetext{
${ }^{6}$ List of TAZs is shown in Table 1

${ }^{7}$ LISA cluster analysis was run using the 999 permutations to control for spurious random spatial affects. The Moran I value is 0.6950 using the 2000 employment density as the measurable variable
} 
The spatial location of the employment center has not changed significantly during the 1990s. Ironically, the location of the employment center extends beyond the traditional central business district within the city. These findings are contrary to the established economic and geography literature that strongly suggests employment suburbanization has and will continue to create employment centers beyond the central city in metropolitan areas. While the use of the TAZ employment density and spatial autocorrelation techniques clearly illustrate the existence of only one significant employment center in the area. Care should be exercised in analysis of the data, as the results are quite sensitive to the spatial measurement unit used, the time period under study and the conceptualization of an employment center and its measurement. Individually and collectively, these issues could lead to misidentification of employment centers in the metropolitan area. Within the context of the Buffalo metropolitan area, while there has been employment suburbanization within the Buffalo metropolitan area, it has been widely dispersed, thus not creating a density of employment that would constitute a suburban employment center. The theory of polycentric employment centers does not hold in the Buffalo metropolitan area.

\section{CONCLUSION}

The Buffalo metropolitan area has experienced continued suburbanization of employment and population during the 1990s. However, employment suburbanization has not reached a level of employment density to create identifiable employment centers in the Buffalo metropolitan area. The lack of identifiable suburban employment centers presents practical problems to transportation and public policy planners in designing policies to link employees to employers beyond the city proper. The city of Buffalo is still home to the largest, and relatively greater, concentration of employment as identified using TAZs extending beyond the boundaries of the traditional central business district. The industrial composition of the employment center reflects a metropolitan economy that is becoming increasingly concentrated on producer services industries and in the public sector. The Buffalo metropolitan economy, while lagging behind that of the national economy, has permanently shifted from one where manufacturing dominated to an metropolitan economy that is becoming increasingly driven by producer services industries. The location preferences for these industries and firms tend to favor suburban locations. Expansion of these industries will undoubtedly lead to greater employment in the suburbs and the likely possibility of development of employment centers along the lines of a multi-nuclei model with specialized employment nodes. To date this has not occurred and the Buffalo metropolitan economy is more reflective of a monocentric model than any other relevant economic model.

\section{REFERENCES}

1. Anderson, Nathan, B. and Bogart, William, T. 2001. The Structure of Sprawl: Identifying and Characterizing Employment Centers in Polycentric Metropolitan Areas. American Journal of Economics and Sociology. 60(1), 147-169

2. Bogart, William, T. and Ferry, William, C. 1999. Employment Centers in Greater Cleveland: Evidence of Evolution in a Formerly Monocentric City. Urban Studies. 36(12), 2099-2110

3. Erickson, Rodney, A. 1986. Multinucleation in Metropolitan Economies. Annals of the Association of American Geographers, 76(3), 331-346

4. Forstall, Richard, L. and Greene, Richard, P. 1997. Defining Job Concentrations: The Los Angeles Case. 18(8), 705-739

5. Giuliano, Genevieve and Small, Kenneth, A. 1991. Subcenters in the Los Angeles region. Regional Science and Urban Economics. 21(2), 163-182

6. McDonald, John, F. and McMillen, Daniel.P. 1990. Employment Subcenters and land values in a Polycentric Urban Area: The Case of Chicago. Environment and Planning:A. 22(12), 1561-1574

7. McDonald, John, F. and Prather, Paul, J. 1994. Suburban Employment Centres: The Case of Chicago. Urban Studies, 31(20), 201-218

8. McMillen, Daniel, P. 2003. Identifying Sub-centers Using Contiguity Matrices. Urban Studies,40(1), 57-69

There was no significant change between the LISA cluster map using 1990 or 2000 employment density data. Thus, 1990 LISA cluster map is not reported in this paper. 
9. White, Sammis, B., Binkley, Lisa, A. and Osterman, Jeffrey, D. 1993. The Sources of Suburban

Employment Growth. Journal of the American Planning Association. 59(2), 193-204

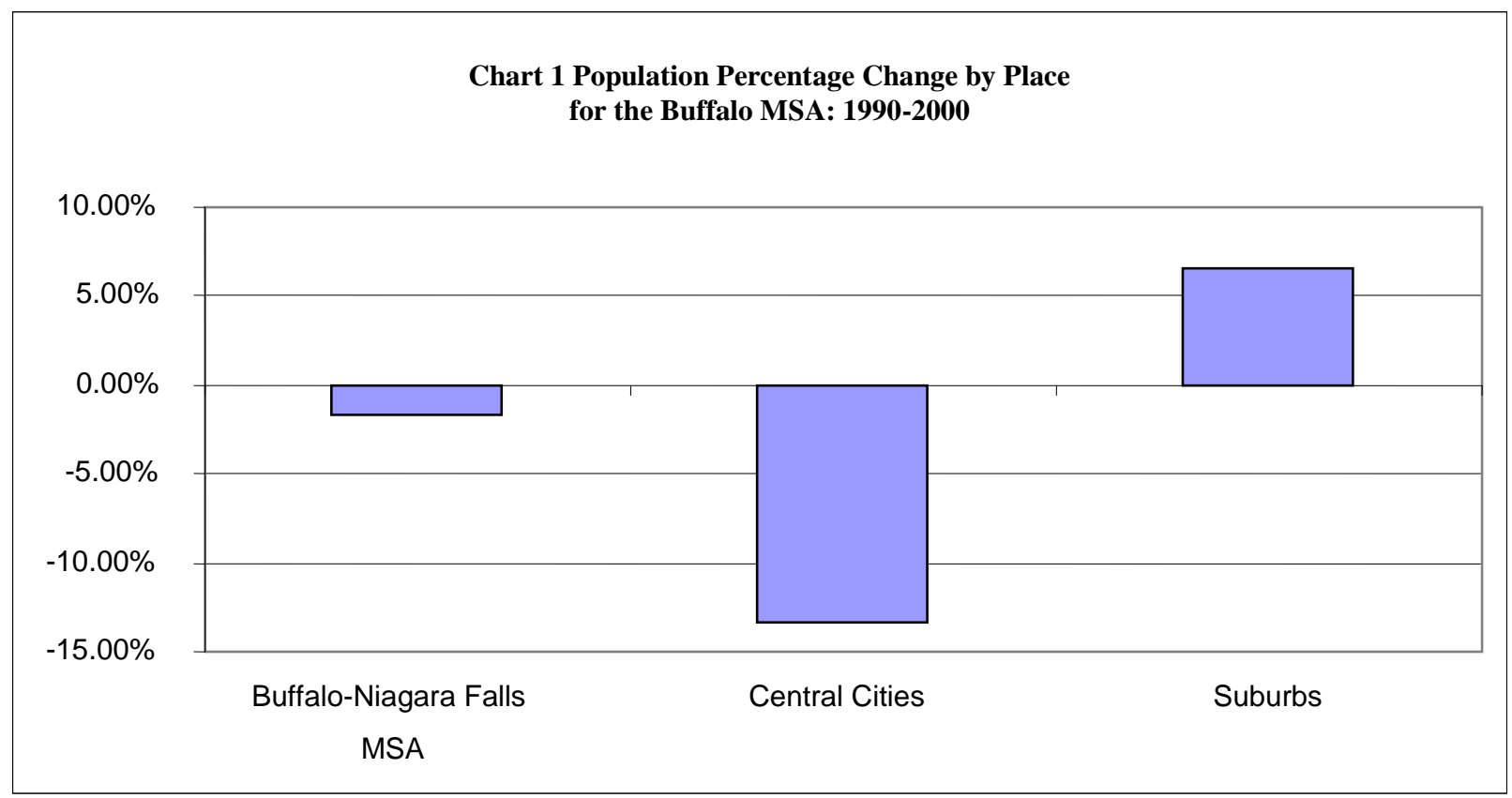

Source: U.S. Census Bureau; 1990 Census, Summary Tape File (STF 3A)Table: P001 and Census 2000, Summary File 3 (SF 3); Table:P1

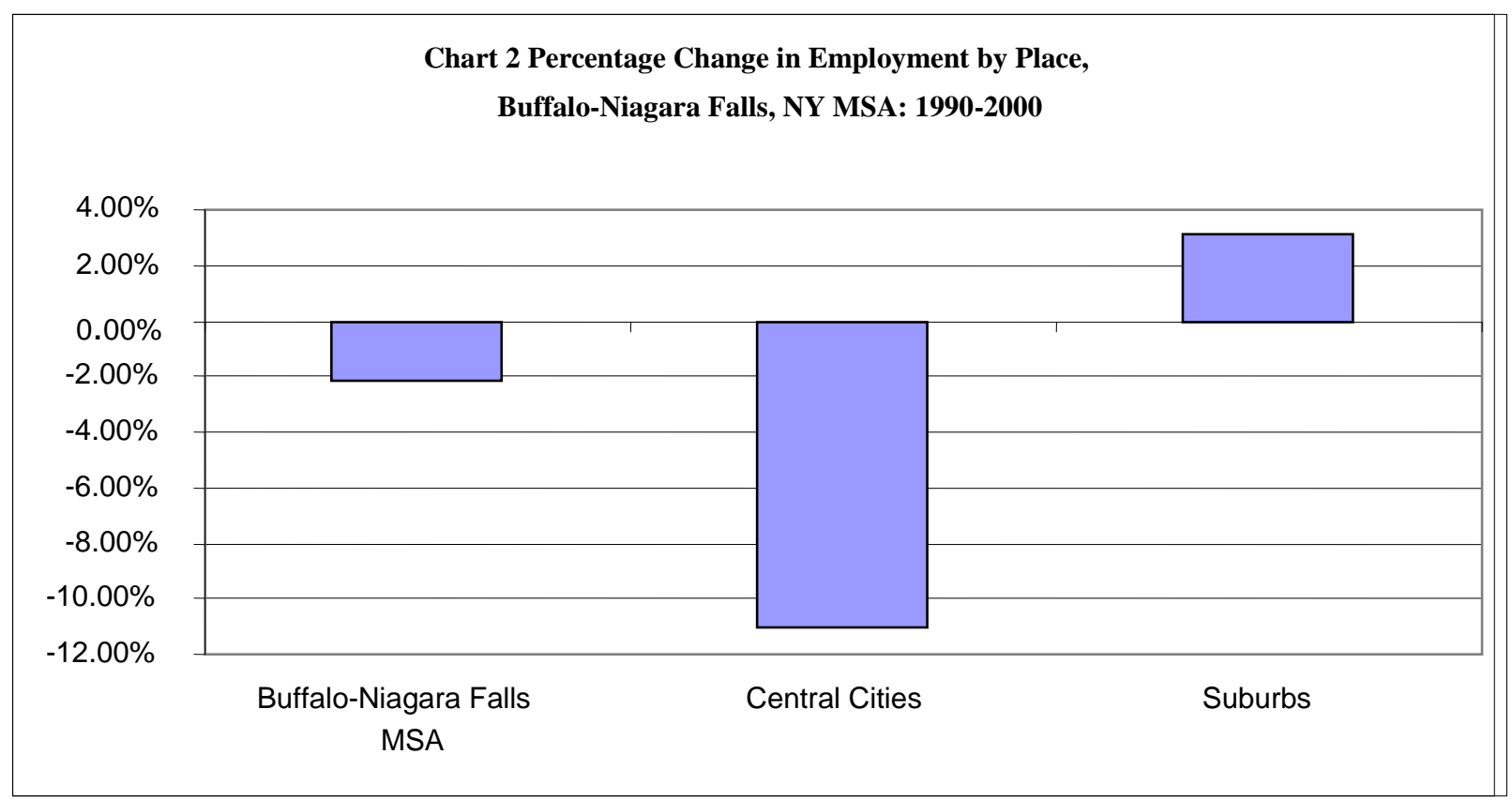

Source: U.S. Census Bureau; 1990 Census, Summary Tape File (STF 3A)Table: P079 and Census 2000, Summary File 3 (SF 3); Table:P51 


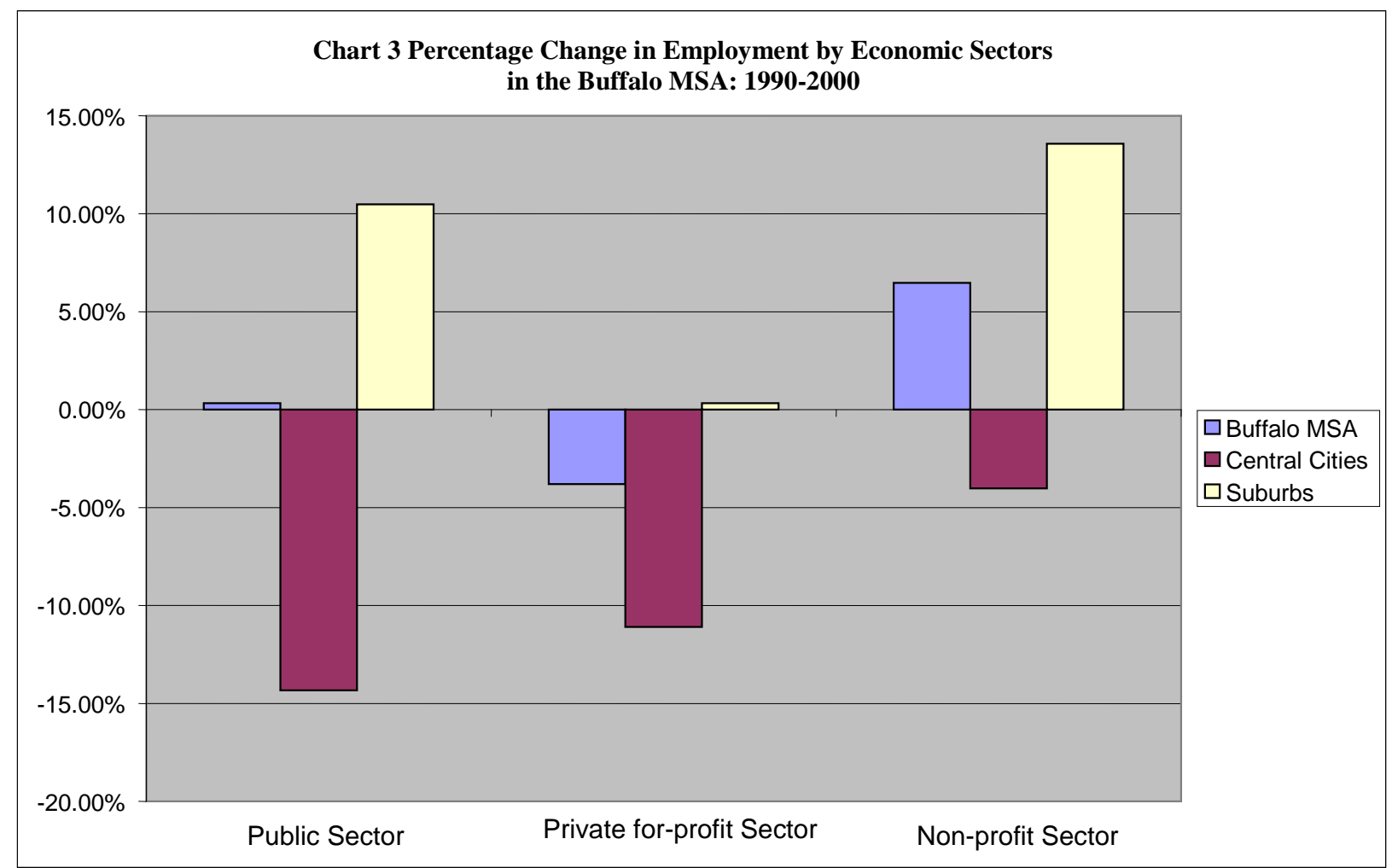

Source: U.S. Census Bureau; 1990 Census, Summary Tape File (STF 3A)Table: P079 and Census 2000, Summary File 3 (SF 3); Table:P51

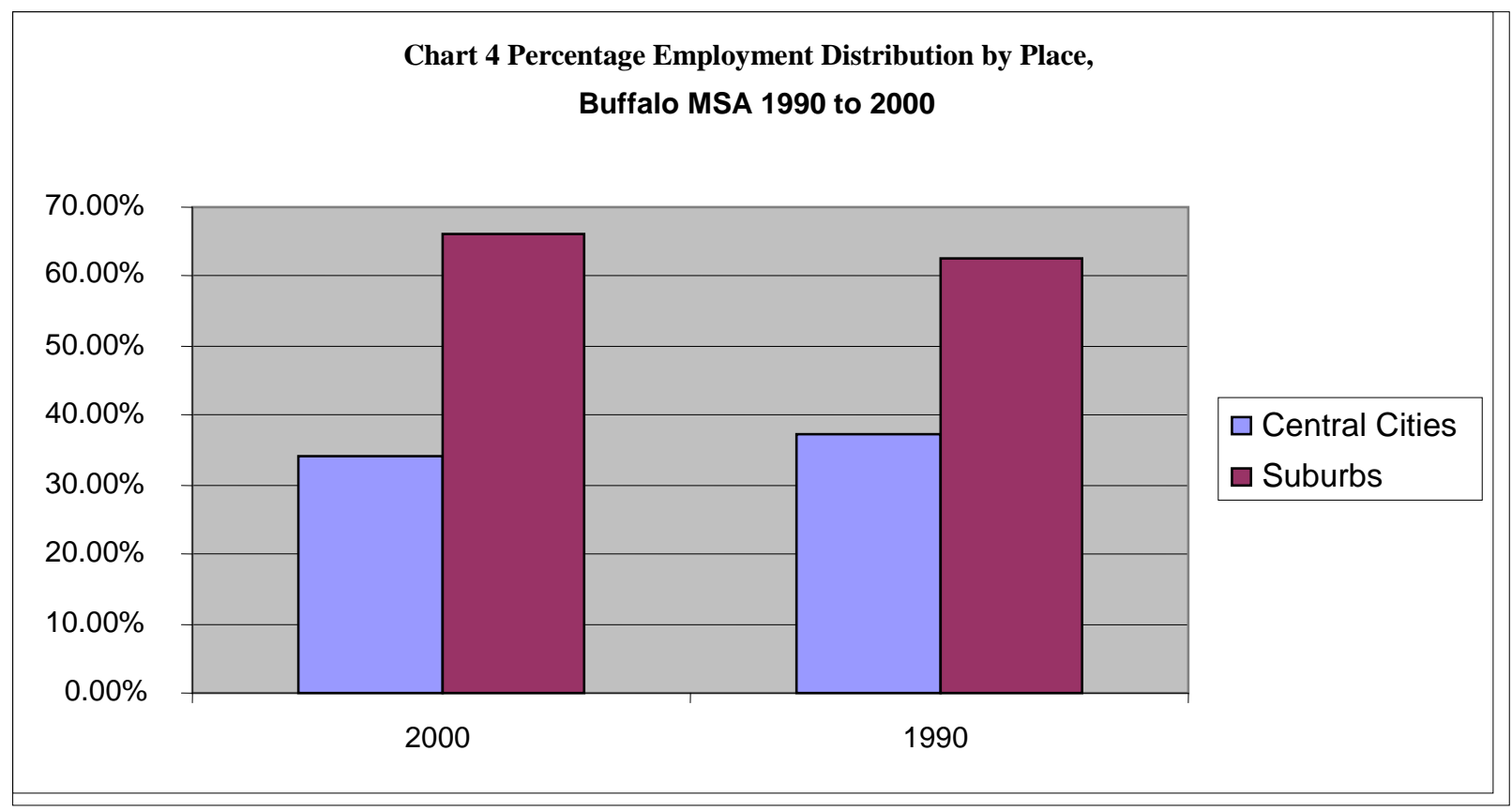

Source: U.S. Census Bureau; 1990 Census, Summary Tape File (STF 3A)Table: P079 and Census 2000, Summary File 3 (SF 3); Table:P51 


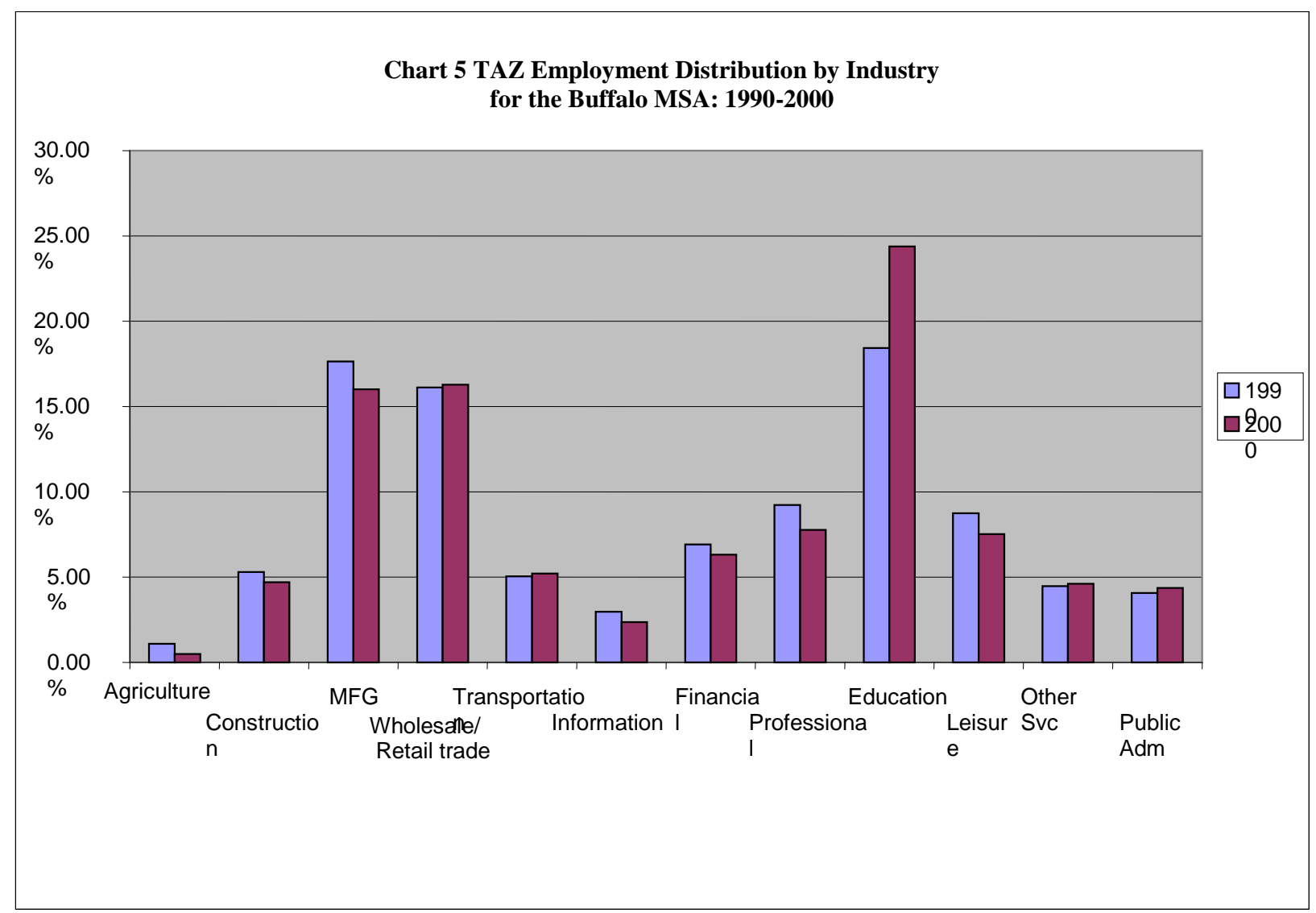

Source: U.S. Census Bureau; 1990 Census, Summary Tape File (STF 3A)Table: P079 and Census 2000,

Summary File 3 (SF 3); Table:P51 
Table 1: List of Employment Density TAZs

Source: TAZ square mileage data was generously provided by the Greater Buffalo-Niagara Regional

\begin{tabular}{|c|c|c|c|}
\hline TAZ_NUM & SQUAREMILE & 2000Employment & 2000Density \\
\hline 1 & 0.03206 & 2800 & 87336 \\
\hline 2 & 0.03663 & 1200 & 32760 \\
\hline 3 & 0.02141 & 1345 & 62821 \\
\hline 4 & 0.01746 & 680 & 38946 \\
\hline 5 & 0.03991 & 6630 & 166124 \\
\hline 6 & 0.04668 & 7725 & 165488 \\
\hline 7 & 0.05182 & 520 & 10035 \\
\hline 11 & 0.03809 & 1985 & 52113 \\
\hline 12 & 0.05492 & 1045 & 19028 \\
\hline 13 & 0.02678 & 695 & 25952 \\
\hline 14 & 0.02715 & 675 & 24862 \\
\hline 16 & 0.09310 & 1660 & 17830 \\
\hline 18 & 0.03453 & 2515 & 72835 \\
\hline 19 & 0.07547 & 3045 & 40347 \\
\hline 20 & 0.14102 & 2810 & 19926 \\
\hline 21 & 0.03308 & 3165 & 95677 \\
\hline 22 & 0.02390 & 1165 & 48745 \\
\hline 27 & 0.28181 & 3610 & 12810 \\
\hline 29 & 0.30739 & 4950 & 16103 \\
\hline 34 & 0.33993 & 7685 & 22608 \\
\hline 55 & 0.15417 & 2800 & 18162 \\
\hline 67 & 0.49484 & 5355 & 10822 \\
\hline 130 & 0.31178 & 3700 & 11867 \\
\hline
\end{tabular}

Transportation Council (GBNRTC) 


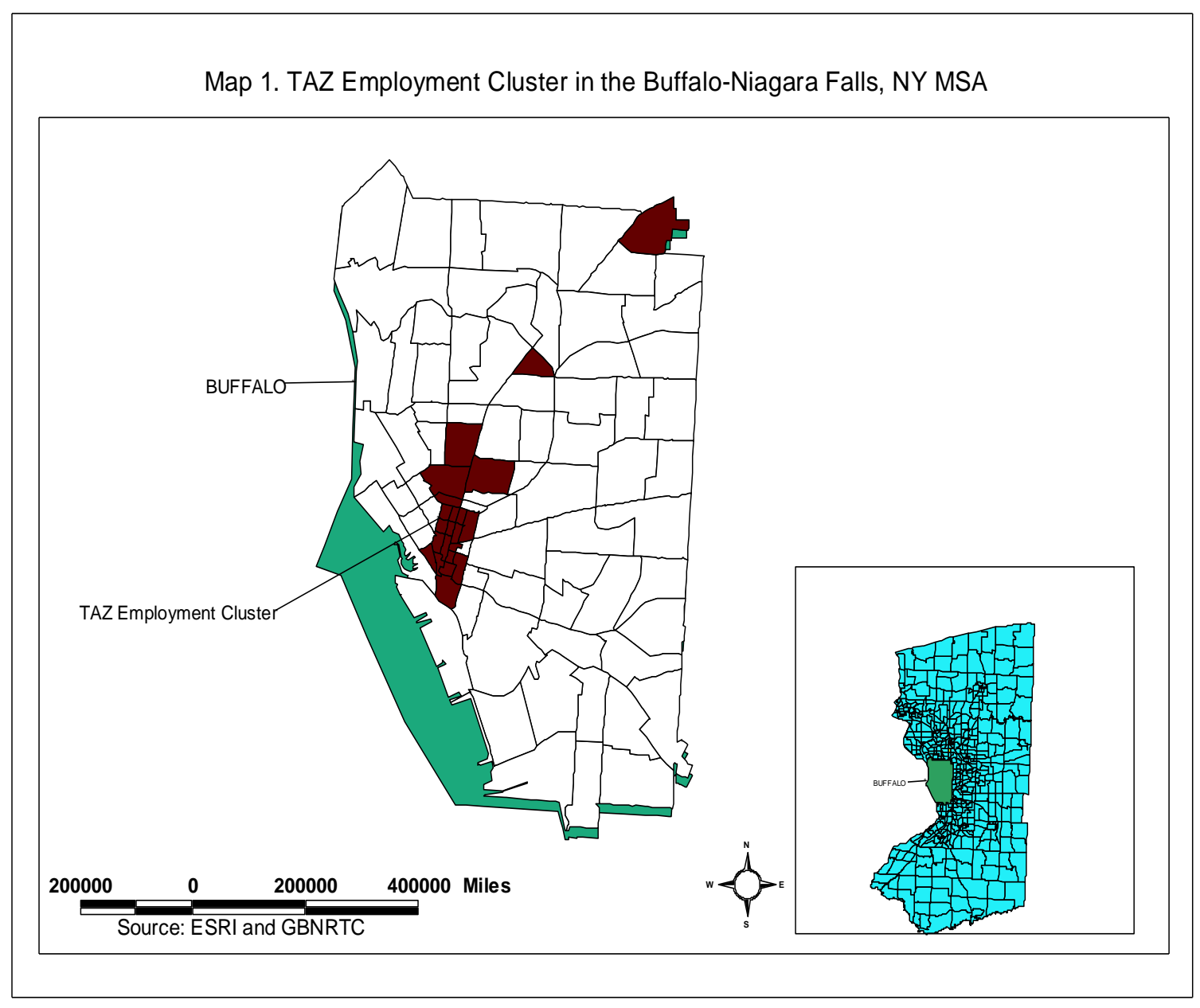


Map 2

LISA Spatial Autocorrelation of 2000 TAZ Employment Density: Buffalo-Niagara MSA

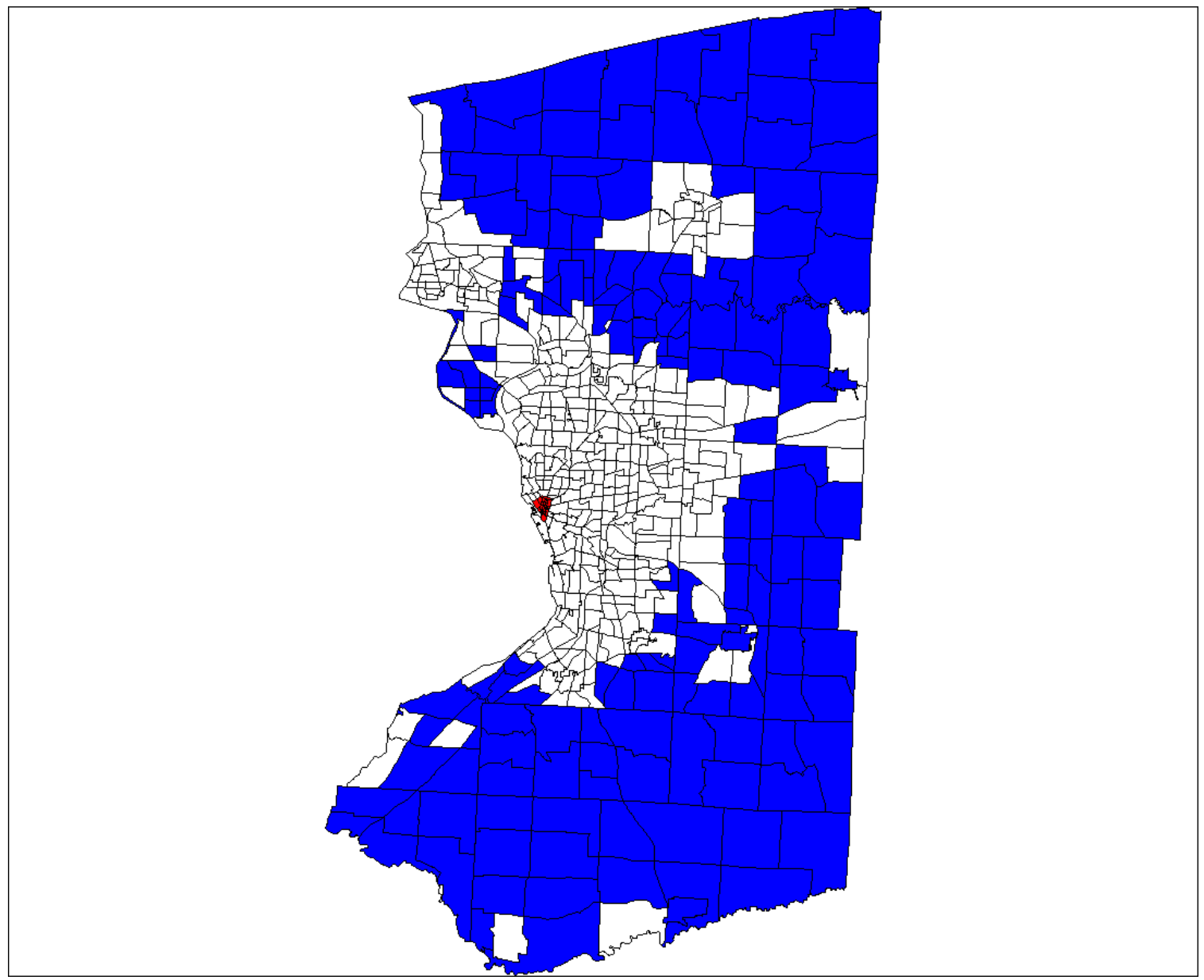

Note: Color code (Red): High-high significant spatial autocorrelation and (Blue): Low- low insignificant spatial autocorrelation

Source: GeoDa https://www.geoda.uiuc.edu/ 


\section{NOTES}

